\title{
Hepatitis B Antigen Positive
}

National Cancer Institute

\section{Source}

National Cancer Institute. Hepatitis B Antigen Positive. NCI Thesaurus. Code C158737.

An indication that hepatitis B antigens have been detected in a sample. 